\title{
Bivariate genetic modelling of the response to an oral glucose tolerance challenge: A gene $\times$ environment interaction approach
}

\author{
G. F. Liu • H. Riese $\cdot$ T. D. Spector $\cdot$ M. Mangino • \\ S. D. O'Dell • R. P. Stolk • H. Snieder
}

Received: 18 November 2008 / Accepted: 17 February 2009 / Published online: 14 March 2009

(C) Springer-Verlag 2009

\begin{abstract}
Aims/hypothesis Twin and family studies have shown the importance of genetic factors influencing fasting and $2 \mathrm{~h}$ glucose and insulin levels. However, the genetics of the physiological response to a glucose load has not been thoroughly investigated.

Methods We studied 580 monozygotic and 1,937 dizygotic British female twins from the Twins UK Registry. The effects of genetic and environmental factors on fasting and $2 \mathrm{~h}$ glucose and insulin levels were estimated using univariate genetic modelling. Bivariate model fitting was used to investigate the glucose and insulin responses to a glucose load, i.e. an OGTT.

Results The genetic effect on fasting and $2 \mathrm{~h}$ glucose and insulin levels ranged between $40 \%$ and $56 \%$ after adjustment for age and BMI. Exposure to a glucose load resulted
\end{abstract}

Electronic supplementary material The online version of this article (doi:10.1007/s00125-009-1325-8) contains supplementary material, which is available to authorised users.

G. F. Liu $(\bowtie) \cdot$ H. Riese $\cdot$ H. Snieder $(\bowtie)$

Department of Epidemiology, Unit of Genetic Epidemiology

and Bioinformatics, University Medical Center Groningen,

University of Groningen, Hanzeplein 1,

PO Box 30.001, 9700 RB Groningen, the Netherlands

e-mail: g.liu@epi.umcg.nl

e-mail: h.snieder@epi.umcg.nl

H. Riese

Department of Psychiatry, Interdisciplinary Center for Psychiatric

Epidemiology, University Medical Center Groningen,

University of Groningen,

Groningen, the Netherlands

T. D. Spector $\cdot$ M. Mangino $\cdot$ H. Snieder

Department of Twin Research and Genetic Epidemiology,

King's College London,

London, UK in the emergence of novel genetic effects on $2 \mathrm{~h}$ glucose independent of the fasting level, accounting for about 55\% of its heritability. For $2 \mathrm{~h}$ insulin, the effect of the same genes that already influenced fasting insulin was amplified by about $30 \%$.

Conclusions/interpretation Exposure to a glucose challenge uncovers new genetic variance for glucose and amplifies the effects of genes that already influence the fasting insulin level. Finding the genes acting on $2 \mathrm{~h}$ glucose independently of fasting glucose may offer new aetiological insight into the risk of cardiovascular events and death from all causes.

Keywords Bivariate genetic modelling $\cdot$ Gene $\times$ environment interaction · Heritability - Insulin - Oral glucose tolerance test · Twin study

S. D. O'Dell

Nutritional Sciences Division, King's College London,

London, UK

\section{R. P. Stolk}

Department of Epidemiology, University Medical Center Groningen, University of Groningen,

Groningen, the Netherlands

H. Snieder

Department of Pediatrics, Georgia Prevention Institute,

Medical College of Georgia,

Augusta, GA, USA 


\section{Abbreviations \\ A Additive genetic effect \\ As Specific additive genetic effect \\ AIC Akaike's information criterion \\ C Shared environmental effect \\ Cs Specific shared environmental effect \\ E Unique environmental effect \\ Es Specific unique environmental effect \\ $h^{2} \quad$ Heritability}

\section{Introduction}

Insulin resistance is the condition in which normal amounts of insulin are inadequate to produce a sufficient response from fat, muscle and liver cells. With increasing insulin resistance, blood glucose levels increase, eventually leading to type 2 diabetes [1]. It is now realised that, together with abdominal obesity, insulin resistance plays a principal role in initiating and perpetuating the pathological manifestations of the metabolic syndrome [2].

The gold standard for the investigation and quantification of insulin resistance employs an euglycaemic clamp technique [3]. Given the complexity of the clamp technique, it is rarely used in clinical practice or epidemiological research. Instead, the OGTT is often used to measure insulin resistance and diagnose diabetes mellitus [4].

Twin studies have been conducted to study the contribution of genetic factors in the pathogenesis of diabetes mellitus and metabolic syndrome. They have demonstrated significant heritable influence on glucose and insulin values, and on insulin resistance and beta cell function calculated from fasting levels or OGTT values [5-15], but there is no clear consensus on the degree to which genes explain the variance of fasting and $2 \mathrm{~h}$ glucose and insulin levels. Most studies have focused on the OGTT and have reported heritabilities of fasting and $2 \mathrm{~h}$ glucose and insulin ranging from $12 \%$ to $62 \%$ (see Electronic Supplementary Material [ESM] Table 1). However, these studies were modest in size and none of them analysed the glucose and insulin responses to the glucose load in a multivariate fashion. Such an approach provides insight into the genetics of the response to this experimentally induced environmental challenge (i.e. gene $\times$ environment interaction) and allows investigation of a number of interesting questions [16-18]. Examples of such questions are (1) whether the influence of genes that act on the fasting level is amplified (or dampened) after exposure to a glucose load, and (2) whether new genetic variance emerges as a result of exposure to the glucose challenge. Investigating these questions would be extremely helpful in designing gene-finding studies, and may aid, for example, the selection of candidate genes and the determination of which phenotype to measure.
In this study we used a bivariate analysis of fasting and $2 \mathrm{~h}$ levels to investigate the $2 \mathrm{~h}$ glucose and insulin responses to the glucose load of an OGTT in a large sample of female twins.

\section{Methods}

Subjects

The Twins UK Registry comprises unselected, mostly female volunteers taken from the general population through national media campaigns in the UK [19]. Written informed consent was obtained from all participants before they entered the study, which was approved by the local research ethics committee.

Zygosity, body composition, and biochemical analyses

Zygosity was determined by the standardised questionnaire and confirmed by a combination of DNA analyses which included full genome scans, the ABI FESTR kit (PerkinElmer Applied Biosystems, Warrington, UK) and the QUAD system (Forensic Science Services, Birmingham, UK). Height was measured to the nearest $0.5 \mathrm{~cm}$ using a wallmounted stadiometer. Weight (light clothing only) was measured to the nearest $0.1 \mathrm{~kg}$ using digital scales. BMI was calculated as weight divided by height squared $\left(\mathrm{kg} / \mathrm{m}^{2}\right)$. A venous blood sample was taken between 08.00 and 10.00 hours after an overnight fast. Within $1 \mathrm{~h}$ of collection, the samples were centrifuged to obtain platelet-poor plasma. Fasting insulin was measured by immunoassay (Abbott Laboratories, Maidenhead, UK) and glucose was measured with an Ektachem 700 multichannel analyser using an enzymatic colorimetric slide assay (Johnson and Johnson Clinical Diagnostic Systems, Amersham, UK). A subsample of twins underwent an OGTT for which glucose and insulin levels were measured before and $2 \mathrm{~h}$ after a $75 \mathrm{~g}$ oral glucose load.

\section{Analytical approach}

The aims of our analyses were twofold: first, to estimate the influence of genetic and environmental factors on fasting and $2 \mathrm{~h}$ glucose and fasting and $2 \mathrm{~h}$ insulin using univariate genetic modelling; and second, based on the results of univariate genetic modelling, to use bivariate model fitting to investigate the glucose and insulin responses to the $75 \mathrm{~g}$ oral glucose load.

Univariate genetic modelling Details of univariate model fitting to twin data have been described elsewhere [20, 21]. In short, the technique is based on comparison of the 
variance-covariance matrices in monozygotic and dizygotic twin pairs and allows separation of the observed phenotypic variance into additive (A) or dominant (D) genetic components and shared $(C)$ or unique (E) environmental components. The last also contains measurement error. Dividing each of these components by the total variance yields the different standardised components of variance. For example, heritability $\left(h^{2}\right)$ can be defined as the proportion of the total variance attributable to additive genetic variance.

Bivariate genetic modelling We used a bivariate analysis of fasting and $2 \mathrm{~h}$ levels of glucose or insulin corresponding to the path diagram shown in Fig. 1. This path diagram depicts the typical structural equation modelling approach to twin data [22]. In this approach, the variance in the observed traits (e.g. fasting glucose and $2 \mathrm{~h}$ glucose) is decomposed into latent additive genetic, shared environmental and unique environmental components. The model is identified because correlations between latent genetic and environmental factors are known for monozygotic and dizygotic twins from biometrical genetic theory. The model implied by the path diagram specifies an expected covariance matrix. Estimates for the path coefficients, i.e. the model parameters (e.g. $a_{11}, c_{11}, e_{11}$ ), are obtained by using a fit function that minimises the difference between the observed covariance matrix and the expected covariance matrix implied by the model.

The relative contribution of genetic variance to the total variance in the fasting glucose level, also known as its heritability, is the effect of the genetic factor A (shown in Fig. 1), and is obtained as the ratio $a_{11}^{2} /\left(a_{11}^{2}+c_{11}^{2}+e_{11}^{2}\right)$. The heritability of $2 \mathrm{~h}$ glucose level is the summed effect of the genetic factors A and As, and is obtained as the ratio of genetic to total variance, or $\left(a_{21}^{2}+a_{22}^{2}\right) /\left(a_{21}^{2}+a_{22}^{2}+c_{21}^{2}+\right.$ $\left.c_{22}^{2}+e_{21}^{2}+e_{22}^{2}\right)$. When going from fasting to the $2 \mathrm{~h}$ level, the effects of the set of genes acting on fasting levels may be amplified $\left(a_{21}>a_{11}\right)$ or dampened $\left(a_{21}<a_{11}\right)$ in response to the glucose load. In addition, entirely new genetic variation may emerge only in response to the glucose load, depicted by factor As. In this case, the path coefficient $a_{22}$ will differ significantly from zero $\left(a_{22}>0\right)$. This part of the total heritability represents the influence of novel genetic effects that are expressed only during challenge and is equal to $a_{22}^{2} /\left(a_{21}^{2}+a_{22}^{2}+c_{21}^{2}+c_{22}^{2}+e_{21}^{2}+e_{22}^{2}\right)$. Both amplifi-

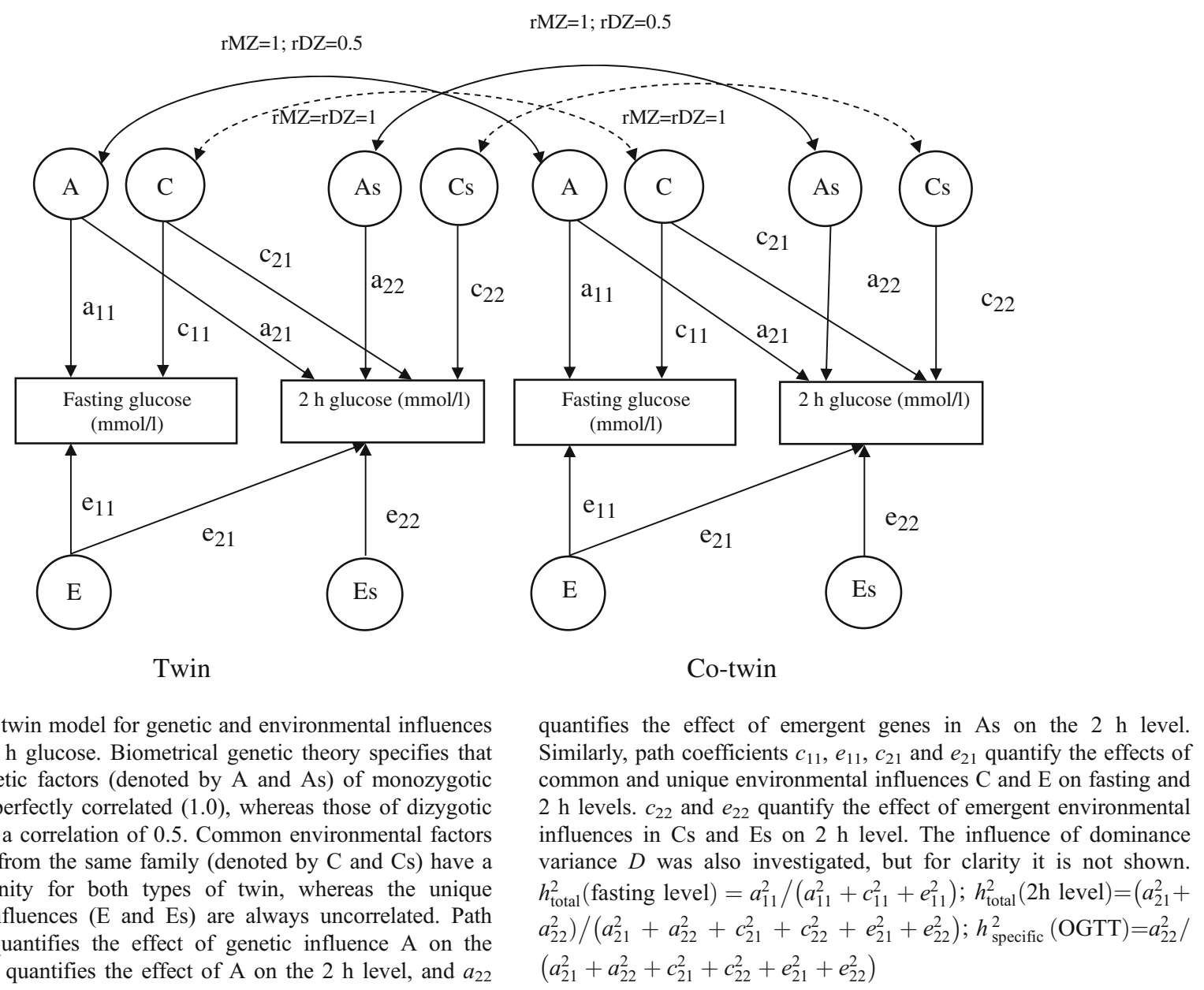


cation and emergence effectively constitute forms of gene $\times$ environment interaction [18].

Before genetic analysis, all variables were logtransformed to obtain better approximations of normal distributions. Effects of age (model 1) and age and BMI (model 2) were regressed out for all variables before using the residuals in model fitting. Models were fitted to the raw data using normal maximum likelihood theory, allowing the use of information for the estimation of variance (but not covariance) provided by unpaired twin observations and/or fasting-only observations.

For genetic modelling, a series of submodels nested within the full-parameter ACE or ADE model were fitted to the variance-covariance matrices. The significances of variance components $\mathrm{A}, \mathrm{C} / \mathrm{D}$ and $\mathrm{E}$ were assessed by testing the deterioration in model fit after each component was dropped from the full ACE or ADE model. Based on the results of univariate genetic modelling, a bivariate decomposition (Fig. 1) was used to model the covariance between fasting and the $2 \mathrm{~h}$ level of glucose or insulin. Emergence of new genetic variance was tested using a submodel that constrained the $a_{22}$ parameter to zero. Amplification (or dampening) of genetic influence was tested using a submodel that constrained $a_{21}$ and $a_{11}$ to be equal. Standard hierarchic $\chi^{2}$ tests were used to select the bestfitting model at a significance level of $p<0.05$ in combination with Akaike's information criterion ( $\mathrm{AIC}=\chi^{2}-2 d f$ ). The model with the lowest AIC reflects the best balance between goodness of fit and parsimony [20].

Preliminary analyses were done using STATA 10 (Stata, College Station, TX, USA). Genetic modelling was carried out with $\mathrm{Mx}$, a computer program specifically designed for the analysis of twin and family data [23].

\section{Results}

General characteristics

The study cohort consisted of female twins whose fasting or $2 \mathrm{~h}$ glucose level or insulin data were available. A total of
226 non-fasting participants $(\leq 8 \mathrm{~h})$, and 33 patients with diabetes were excluded from the analysis. The total number of twins included in the final analysis was 580 monozygotic twins (280 twin pairs and 20 unpaired twins) and 1,937 dizygotic twins (933 twin pairs and 71 unpaired twins). Of these participants, 308 monozygotic twins (150 twin pairs and eight unpaired twins) and 891 dizygotic twins (431 twin pairs and 29 unpaired twins) underwent an OGTT and had measurements of $2 \mathrm{~h}$ glucose available. Most of these twins [181 monozygotic ( 88 twin pairs and five unpaired twins) and 631 dizygotic twins (310 twin pairs and 11 unpaired twins)] also had their $2 \mathrm{~h}$ insulin measured. General characteristics of these twins are shown in Table 1. Fasting and $2 \mathrm{~h}$ glucose and insulin were very similar in the two zygosity groups; monozygotic twins were slightly older and had a lower BMI than dizygotic twins. However, we adjusted for age and BMI in our analyses (see blow).

\section{Univariate genetic modelling}

Table 2 presents the twin correlations for the two zygosity groups adjusted for age and age and BMI, respectively. For all measures, intraclass correlations in monozygotic twins were consistently larger than in dizygotic twins, indicating an important contribution of genetic factors.

This pattern was confirmed by the univariate model fitting. Parameter estimates of the best-fitting univariate models and their $95 \%$ confidence interval (CI) are shown in Table 3. There were significant genetic components for all variables, whether after adjustment for age or after adjustment for age and BMI. For fasting glucose and fasting insulin, a full ACE model was chosen as the bestfitting model, on the basis of a hierarchic $\chi^{2}$ test and lowest AIC. After adjustment for age, the heritabilities of fasting glucose and fasting insulin were estimated at $38 \%$ and $45 \%$, respectively. In the best-fitting model for $2 \mathrm{~h}$ glucose and $2 \mathrm{~h}$ insulin, $\mathrm{C}$ could be dropped without deterioration in fit $\left(\chi^{2}(1)=0.0, p=1.0\right)$. The heritabilities of $2 \mathrm{~h}$ glucose and insulin were estimated at $42 \%$ and $51 \%$ respectively. Heritability estimates after additional adjustment for BMI decreased slightly except for the heritability of fasting
Table 1 Characteristics of monozygotic and dizygotic twins in the study sample

$n$, number of participants (nonfasting participants $[\leq 8 \mathrm{~h}]$ and patients with diabetes were excluded)

\begin{tabular}{|c|c|c|c|c|}
\hline \multirow[t]{2}{*}{ Characteristic } & \multicolumn{2}{|c|}{ Monozygotic } & \multicolumn{2}{|c|}{ Dizygotic } \\
\hline & $n$ & Mean \pm SD & $n$ & Mean \pm SD \\
\hline Age (years) & 580 & $49.2 \pm 14.1$ & 1937 & $46.9 \pm 11.8$ \\
\hline BMI $\left(\mathrm{kg} / \mathrm{m}^{2}\right)$ & 580 & $24.4 \pm 3.8$ & 1937 & $25.1 \pm 4.6$ \\
\hline Fasting glucose $(\mathrm{mmol} / \mathrm{l})$ & 580 & $4.5 \pm 0.6$ & 1937 & $4.5 \pm 0.5$ \\
\hline Fasting insulin $(\mathrm{pmol} / \mathrm{ml})$ & 430 & $49.3 \pm 43.5$ & 1744 & $47.3 \pm 34.0$ \\
\hline $2 \mathrm{~h}$ glucose $(\mathrm{mmol} / \mathrm{l})$ & 308 & $5.2 \pm 1.6$ & 891 & $5.2 \pm 1.1$ \\
\hline $2 \mathrm{~h}$ insulin $(\mathrm{pmol} / \mathrm{ml})$ & 181 & $238.2 \pm 158.6$ & 631 & $234.7 \pm 177.0$ \\
\hline
\end{tabular}


Table 2 Intraclass correlations $(95 \% \mathrm{CI})$ for monozygotic and dizygotic twins

\begin{tabular}{|c|c|c|c|c|c|c|}
\hline \multirow[t]{2}{*}{ Measure } & \multicolumn{2}{|l|}{ No. twin pairs } & \multicolumn{2}{|l|}{ Age-adjusted } & \multicolumn{2}{|c|}{ Age- and BMI-adjusted } \\
\hline & Monozygotic & Dizygotic & Monozygotic & Dizygotic & Monozygotic & Dizygotic \\
\hline Fasting glucose (mmol/l) & 280 & 933 & $0.72(0.66-0.77)$ & $0.50(0.46-0.55)$ & $0.72(0.66-0.78)$ & $0.52(0.47-0.56)$ \\
\hline Fasting insulin (pmol/ml) & 206 & 837 & $0.65(0.57-0.73)$ & $0.37(0.31-0.43)$ & $0.63(0.55-0.71)$ & $0.38(0.33-0.44)$ \\
\hline $2 \mathrm{~h}$ glucose $(\mathrm{mmol} / \mathrm{l})$ & 150 & 431 & $0.48(0.36-0.60)$ & $0.16(0.06-0.25)$ & $0.47(0.34-0.59)$ & $0.15(0.06-0.25)$ \\
\hline $2 \mathrm{~h}$ insulin $(\mathrm{pmol} / \mathrm{ml})$ & 88 & 310 & $0.52(0.36-0.67)$ & $0.24(0.14-0.35)$ & $0.49(0.34-0.65)$ & $0.24(0.14-0.35)$ \\
\hline
\end{tabular}

insulin, which showed a considerable drop from 0.45 to 0.35. Dominant genetic influences were tested for all variables (ADE vs $\mathrm{AE}$ ) but never contributed significantly (data not shown).

\section{Bivariate genetic modelling}

Based on the results of univariate model fitting, using the model depicted in Fig. 1, a series of submodels nested within the full model were tested for both glucose and insulin. Guided by our univariate model fitting results we first tested whether we could drop the influence of $\mathrm{C}$ on $2 \mathrm{~h}$ glucose and insulin (i.e. $c_{21}$ and $c_{22}$ ). Subsequently we tested the significance of the genetic correlation $\left(a_{21}\right)$, novel genetic effects $\left(a_{22}\right)$ and unique environmental correlation $\left(e_{21}\right)$. The results showed that $c_{21}$ and $c_{22}$ could be dropped with no deterioration in model fit for both glucose and insulin (ESM Table 2, model 2). For glucose, the path coefficients $a_{21}$ (model 3) and $a_{22}$ (model 4) could not be dropped, which means there was a significant genetic effect of $\mathrm{A}$ on $2 \mathrm{~h}$ glucose and a significant novel genetic effect (As) on $2 \mathrm{~h}$ glucose. Finally, $e_{21}$ (model 5) could not be dropped without a deterioration in model fit. For insulin, the path coefficient $a_{21}$ could not be dropped (model 3), which means there was a significant effect of $\mathrm{A}$ on $2 \mathrm{~h}$ insulin level. However, $a_{22}$ and $e_{21}$ could be dropped without worsening the model fit, meaning there was no significant novel genetic effect in response to the glucose load, and no significant unique environmental correlation between fasting and $2 \mathrm{~h}$ insulin.

Parameter estimates of best-fitting bivariate models are shown in Table 4. Significant heritability was found for fasting and $2 \mathrm{~h}$ glucose and insulin. After adjustment for age and BMI, the heritability of $2 \mathrm{~h}$ glucose $(0.42)$ was similar to that of fasting glucose $(0.40)$. The heritability of $2 \mathrm{~h}$ insulin (0.56) was a little higher than that of fasting insulin (0.44). The parameter estimates after adjustment for age were similar to those that were additionally adjusted for BMI.

Table 5 presents additional characteristics of best-fitting bivariate models for the response to an oral glucose load. A common set of genes was found to influence both fasting and $2 \mathrm{~h}$ levels of glucose. Similar results were obtained for insulin. This factor represents genes acting on both fasting and $2 \mathrm{~h}$ levels and corresponds to factor A in Fig. 1. Amplification of the effect of genes that already influence the fasting glucose level was not significant (after adjustment for age and BMI, $\Delta \chi^{2}(1)=0.93, p=0.34$ ), while exposure to a glucose load significantly amplified the effect of genes that already influence fasting insulin (after adjustment for age and BMI, $\Delta \chi^{2}(1)=13.38, p=0.0003$ ). Furthermore, for glucose, exposure to a glucose load uncovered new genetic variance corresponding to factor As in Fig. 1; the specific heritability due to genes emerging
Table 3 Parameter estimates and $95 \%$ CIs of the best-fitting univariate models

\begin{tabular}{llll}
\hline Measure & $h^{2}(95 \% \mathrm{CI})$ & $c^{2}(95 \% \mathrm{CI})$ & $e^{2}(95 \% \mathrm{CI})$ \\
\hline $\begin{array}{l}\text { Age-adjusted } \\
\text { Fasting glucose }(\mathrm{mmol} / \mathrm{l})\end{array}$ & $0.38(0.25-0.51)$ & $0.32(0.22-0.42)$ & $0.30(0.25-0.35)$ \\
Fasting insulin $(\mathrm{pmol} / \mathrm{ml})$ & $0.45(0.26-0.63)$ & $0.16(0.02-0.29)$ & $0.39(0.33-0.48)$ \\
$2 \mathrm{~h}$ glucose $(\mathrm{mmol} / \mathrm{l})$ & $0.42(0.31-0.52)$ & & $0.58(0.48-0.69)$ \\
$2 \mathrm{~h}$ insulin $(\mathrm{pmol} / \mathrm{ml})$ & $0.51(0.39-0.62)$ & & $0.49(0.38-0.62)$ \\
Age- and BMI-adjusted & & & $0.29(0.25-0.35)$ \\
Fasting glucose $\mathrm{mmol} / 1$ & $0.37(0.24-0.50)$ & $0.34(0.24-0.43)$ & $0.43(0.36-0.51)$ \\
Fasting insulin $(\mathrm{pmol} / \mathrm{ml})$ & $0.35(0.15-0.53)$ & $0.22(0.09-0.36)$ & $0.59(0.49-0.70)$ \\
$2 \mathrm{~h}$ glucose $(\mathrm{mmol} / \mathrm{l})$ & $0.41(0.30-0.51)$ & & $0.50(0.39-0.63)$ \\
$2 \mathrm{~h}$ insulin $(\mathrm{pmol} / \mathrm{ml})$ & $0.50(0.37-0.61)$ & & \\
\hline
\end{tabular}


Table 4 Parameter estimates $(95 \% \mathrm{CI})$ of best-fitting bivariate models

\begin{tabular}{|c|c|c|c|c|c|}
\hline \multirow[t]{2}{*}{ Measure } & \multicolumn{3}{|l|}{ Fasting level } & \multicolumn{2}{|l|}{$2 \mathrm{~h}$ level } \\
\hline & $h^{2}(95 \% \mathrm{CI})$ & $c^{2}(95 \% \mathrm{CI})$ & $e^{2}(95 \% \mathrm{CI})$ & $h^{2}(95 \% \mathrm{CI})$ & $e^{2}(95 \% \mathrm{CI})$ \\
\hline \multicolumn{6}{|c|}{ Age-adjusted } \\
\hline Glucose & $0.42(0.29-0.54)$ & $0.29(0.19-0.39)$ & $0.29(0.25-0.35)$ & $0.43(0.32-0.53)$ & $0.57(0.47-0.68)$ \\
\hline Insulin & $0.49(0.40-0.58)$ & $0.14(0.07-0.21)$ & $0.37(0.32-0.43)$ & $0.57(0.47-0.67)$ & $0.43(0.33-0.53)$ \\
\hline \multicolumn{6}{|c|}{ Age- and BMI-adjusted } \\
\hline Glucose & $0.40(0.28-0.53)$ & $0.31(0.21-0.40)$ & $0.29(0.24-0.34)$ & $0.42(0.31-0.52)$ & $0.58(0.48-0.69)$ \\
\hline Insulin & $0.44(0.35-0.54)$ & $0.17(0.09-0.24)$ & $0.39(0.34-0.45)$ & $0.56(0.45-0.66)$ & $0.44(0.34-0.55)$ \\
\hline
\end{tabular}

was $23 \%(95 \%$ CI $0.06-0.36)$. Comparing this with the total heritability of $2 \mathrm{~h}$ glucose, which was $42 \%$, the genetic effect due to genes emerging accounted for about $55 \%$ of the total heritability of $2 \mathrm{~h}$ glucose. For insulin, no significant influence of new genetic variance was found.

\section{Discussion}

In this study, we estimated the relative influences of genetic and environmental factors on fasting and $2 \mathrm{~h}$ glucose and insulin levels in a large sample of British female twins. Furthermore, we used bivariate model fitting to investigate the glucose and insulin response to a $75 \mathrm{~g}$ oral glucose load. We found that there were significant genetic components for fasting and $2 \mathrm{~h}$ glucose and insulin levels. Key findings of this study derived from the bivariate model fitting are as follows: (1) a common set of genes was found to influence both fasting and $2 \mathrm{~h}$ levels of glucose, and similar results were obtained for insulin; (2) for glucose, exposure to a glucose load uncovered new genetic variance; (3) for insulin, a glucose challenge significantly amplified the effect of genes that already influence the fasting insulin level.

Previous twin studies showed a significant effect of genetic factors on fasting and $2 \mathrm{~h}$ glucose and insulin levels
$[5,6,8-11]$. In this British female twin cohort, we found significant effects of genetic factors on fasting and $2 \mathrm{~h}$ glucose and insulin after adjustment for age and additional adjustment for BMI, which are largely in agreement with previous studies $[9,11]$. We found that heritability estimates showed a considerable drop, of around $10 \%$, for fasting insulin after additional adjustment for BMI. This indicates that part of the heritability for fasting insulin can be attributed to genes for obesity. The fat mass and obesity associated gene $(F T O)$ is a practical example of such a gene. Initially discovered as a type 2 diabetes gene, it was later found that its effect was mediated by obesity [24]. In fitting the univariate model, we found that the best-fitting model for fasting glucose and insulin was the ACE model, which is different from the best-fitting AE model for fasting glucose and insulin that others found [9, 11]. This might be explained by our much larger sample size, which provided enough power to detect the effect of a shared environment.

In designing gene-finding studies, it may be helpful to have prior knowledge from twin studies guiding the choice of phenotypes and the type of genes to look for, i.e. amplified or emerging genes. For instance, if only amplification had been found with small effects on total genetic variance, adding OGTT to the experimental protocol would not be worthwhile. Vice versa, if new genetic variance emerges

Table 5 Bivariate heritability estimates of the response to an OGTT of best-fitting models

\begin{tabular}{lllll}
\hline Measure & $\begin{array}{l}\text { Fasting } h^{2} \\
(95 \% \mathrm{CI})\end{array}$ & $2 \mathrm{~h} h^{2}(95 \% \mathrm{CI})$ & $\begin{array}{l}\text { Amplification of genes acting } \\
\text { on fasting level }\end{array}$ & $\begin{array}{l}\text { Specific } h^{2} \text { due to genes emerging } \\
(95 \% \mathrm{CI})\end{array}$ \\
\hline $\begin{array}{l}\text { Age-adjusted } \\
\text { Glucose }\end{array}$ & $0.42(0.29-0.54)$ & $0.43(0.32-0.53)$ & $\mathrm{NS}$ & $0.24(0.07-0.36)$ \\
Insulin & $0.49(0.40-0.58)$ & $0.57(0.47-0.67)$ & $a_{21} / a_{11}=1.31$ & $\mathrm{NS}$ \\
Age- and BMI-adjusted & & & $0.23(0.06-0.36)$ \\
Glucose & $0.40(0.28-0.53)$ & $0.42(0.31-0.52)$ & $\mathrm{NS}$ & $\mathrm{NS}$ \\
Insulin & $0.44(0.35-0.55)$ & $0.56(0.45-0.66)$ & $a_{21} / a_{11}=1.46$ & \\
\hline
\end{tabular}

${ }^{\text {a }}$ Heritability estimate for genes emerging on exposure to OGTT

NS, not significant 
during exposure to a glucose load, these genes can only be found when the system is challenged environmentally.

In our study, for insulin, no new genetic variance was found as a result of exposure to a glucose load. We estimated specific heritabilities of only 0.06 (95\% CI 0.00 $0.24)$ after adjustment for age and 0.00 (95\% CI 0.00-0.21) after additional adjustment for BMI. Thus, it is unlikely that we missed the effects of emerging genes on $2 \mathrm{~h}$ insulin due to power limitations of our study. For glucose, we found that, exposure to a glucose load uncovered new genetic variance, accounting for about $55 \%$ of the total heritability of $2 \mathrm{~h}$ glucose. It would therefore be interesting if genes were detected that acted on $2 \mathrm{~h}$ glucose distinct from those acting on fasting glucose. The DECODE Study Group [25] and Qiao et al. [26] found that asymptomatic diabetes, as well as IGT defined by the $2 \mathrm{~h}$ glucose criterion alone, increased the risk of death from cardiovascular and all causes, independently of other known risk factors and the level of fasting glucose, whereas mortality associated with the fasting glucose concentration depended largely on the level of $2 \mathrm{~h}$ glucose. They concluded that $2 \mathrm{~h}$ glucose was superior to fasting glucose in assessing the risk of future cardiovascular disease events and mortality from all causes. This might be explained to some extent by the genetic effects acting on $2 \mathrm{~h}$ glucose during exposure to a glucose load being distinct from those acting on fasting glucose. Genome-wide association studies have found susceptibility loci associated with type 2 diabetes [27] and cardiovascular disease [28], but no genome-wide association studies of $2 \mathrm{~h}$ glucose have been conducted to date. Finding genes specific to $2 \mathrm{~h}$ glucose would offer new aetiological insight into the risk of cardiovascular events and death from all causes.

The study by Katoh et al. [11] is the only other study that included bivariate analysis of OGTT data. They estimated the genetic correlation coefficient between fasting insulin and $2 \mathrm{~h}$ insulin levels through bivariate genetic analyses, and found that they were influenced by a shared genetic factor, which is in line with our finding. However they did not investigate whether there is amplification or new genetic variance emerging due to exposure to a glucose load. Furthermore, they did not report bivariate results for fasting and $2 \mathrm{~h}$ glucose in their study because of power limitations.

To our knowledge, our study is the largest twin study to report heritabilities of fasting and $2 \mathrm{~h}$ glucose and insulin. These British female twins have been shown to be comparable to the age-matched general population in the UK in terms of disease-related and lifestyle characteristics [29]. However, our results cannot necessarily be extrapolated to males, as females may respond to a glucose load differently from males [30].

In summary, our key findings are that a common set of genes was found to influence fasting and $2 \mathrm{~h}$ glucose and insulin levels, and that exposure to a $75 \mathrm{~g}$ oral glucose load uncovers new genetic variance for glucose and amplifies the effect of genes that already influence the fasting level of insulin. This has clear implications for attempts to find the genes influencing insulin resistance through linkage or association approaches, and it would be useful to detect genes acting on $2 \mathrm{~h}$ glucose distinct from genes acting on fasting glucose.

Acknowledgements The Department of Twin Research and Genetic Epidemiology received support from the Welcome Trust and the European Union 5th Framework Programme GenomEUtwin (QLG2CT-2002-01254) and EuroClot project LSHM-CT-2004-005268. This work was also funded by a National Institute for Health Research Biomedical Centre award to King's College London and Guys and St Thomas' Hospital Trust.

Duality of interest The authors declare that there is no duality of interest associated with this manuscript.

\section{References}

1. Haffner SM, D’Agostino R Jr, Mykkanen L et al (1999) Insulin sensitivity in subjects with type 2 diabetes. Relationship to cardiovascular risk factors: the Insulin Resistance Atherosclerosis Study. Diabetes Care 22:562-568

2. Lann D, LeRoith D (2007) Insulin resistance as the underlying cause for the metabolic syndrome. Med Clin North Am 91:10631077

3. Hanley AJ, Williams K, Gonzalez C et al (2003) Prediction of type 2 diabetes using simple measures of insulin resistance: combined results from the San Antonio Heart Study, the Mexico City Diabetes Study, and the Insulin Resistance Atherosclerosis Study. Diabetes 52:463-469

4. World Health Organization (1999) Definition, diagnosis and classification of diabetes mellitus and its complications: report of a WHO consultation. World Health Organization, Geneva

5. Mayer EJ, Newman B, Austin MA et al (1996) Genetic and environmental influences on insulin levels and the insulin resistance syndrome: an analysis of women twins. Am J Epidemiol 143:323-332

6. Snieder H, Boomsma DI, van Doornen LJ, Neale MC (1999) Bivariate genetic analysis of fasting insulin and glucose levels. Genet Epidemiol 16:426-446

7. Souren NY, Paulussen AD, Loos RJ et al (2007) Anthropometry, carbohydrate and lipid metabolism in the East Flanders Prospective Twin Survey: heritabilities. Diabetologia 50:2107-2116

8. Poulsen P, Kyvik KO, Vaag A, Beck-Nielsen H (1999) Heritability of type II (non-insulin-dependent) diabetes mellitus and abnormal glucose tolerance - a population-based twin study. Diabetologia 42:139-145

9. Baird J, Osmond C, MacGregor A, Snieder H, Hales CN, Phillips DI (2001) Testing the fetal origins hypothesis in twins: the Birmingham Twin Study. Diabetologia 44:33-39

10. Schousboe K, Visscher PM, Henriksen JE, Hopper JL, Sorensen TI, Kyvik KO (2003) Twin study of genetic and environmental influences on glucose tolerance and indices of insulin sensitivity and secretion. Diabetologia 46:1276-1283

11. Katoh S, Lehtovirta M, Kaprio J et al (2005) Genetic and environmental effects on fasting and postchallenge plasma glucose and serum insulin values in Finnish twins. J Clin Endocrinol Metab 90:2642-2647 
12. Benyamin B, Sorensen TI, Schousboe K, Fenger M, Visscher PM, Kyvik KO (2007) Are there common genetic and environmental factors behind the endophenotypes associated with the metabolic syndrome? Diabetologia 50:1880-1888

13. Lehtovirta M, Kaprio J, Groop L, Trombetta M, Bonadonna RC (2005) Heritability of model-derived parameters of beta cell secretion during intravenous and oral glucose tolerance tests: a study of twins. Diabetologia 48:1604-1613

14. Poulsen P, Vaag A, Kyvik K, Beck-Nielsen H (2001) Genetic versus environmental aetiology of the metabolic syndrome among male and female twins. Diabetologia 44:537-543

15. Lehtovirta M, Kaprio J, Forsblom C, Eriksson J, Tuomilehto J, Groop L (2000) Insulin sensitivity and insulin secretion in monozygotic and dizygotic twins. Diabetologia 43:285-293

16. Snieder H, Wang X, Lagou V, Penninx BWJH, Riese H, Hartman CA (2008) Role of genestress interactions in gene finding studies. In: Rutter M (ed) Genetic effects on environmental vulnerability to disease. Wiley, Chichester, pp 71-82

17. Gould TD, Gottesman II (2006) Psychiatric endophenotypes and the development of valid animal models. Genes Brain Behav 5:113-119

18. De Geus EJ, Kupper N, Boomsma DI, Snieder H (2007) Bivariate genetic modeling of cardiovascular stress reactivity: does stress uncover genetic variance? Psychosom Med 69:356-364

19. Spector TD, Williams FM (2006) The UK Adult Twin Registry (TwinsUK). Twin Res Hum Genet 9:899-906

20. Neale MCCL (1992) Methodology for genetic studies of twins and families. Kluwer, Dordrecht, Netherlands

21. Snieder H, MacGregor AJ (2005) Twin methodology. Wiley, Chichester
22. McCaffery JM, Snieder H, Dong Y, de Geus E (2007) Genetics in psychosomatic medicine: research designs and statistical approaches. Psychosom Med 69:206-216

23. Neale MCBS, Xie G, Maes HH (2004) Mx: statistical modeling. Virginia Commonwealth University, VA

24. Frayling TM, Timpson NJ, Weedon MN et al (2007) A common variant in the FTO gene is associated with body mass index and predisposes to childhood and adult obesity. Science 316:889-894

25. The DECODE Study Group (2001) Glucose tolerance and cardiovascular mortality: comparison of fasting and 2 hour diagnostic criteria. Arch Intern Med 161:397-405

26. Qiao Q, Pyorala K, Pyorala M et al (2002) Two-hour glucose is a better risk predictor for incident coronary heart disease and cardiovascular mortality than fasting glucose. Eur Heart J 23:1267-1275

27. Zeggini E, Scott LJ, Saxena R et al (2008) Meta-analysis of genome-wide association data and large-scale replication identifies additional susceptibility loci for type 2 diabetes. Nat Genet 40:638-645

28. Samani NJ, Erdmann J, Hall AS et al (2007) Genomewide association analysis of coronary artery disease. N Engl $\mathrm{J}$ Med 357:443-453

29. Andrew T, Hart DJ, Snieder H, de Lange M, Spector TD, MacGregor AJ (2001) Are twins and singletons comparable? A study of disease-related and lifestyle characteristics in adult women. Twin Res 4:464-477

30. Van Gaal L, Vansant G, van Acker K, de Leeuw I (1991) Decreased hepatic insulin extraction in upper body obesity: relationship to unbound androgens and sex hormone binding globulin. Diabetes Res Clin Pract 12:99-106 